\title{
HEXACO Personality Traits and Job Seekers' Networking Behavior: The Effect of Network Size*
}

\author{
Khac Thanh MAI ${ }^{1}$, Son-Tung LE ${ }^{2}$, Manh-Trung PHUNG ${ }^{3}$, Thi Thuy Hong NGUYEN ${ }^{4}$
}

Received: September 01, 2020 Revised: October 26, 2020 Accepted: November 05, 2020

\begin{abstract}
Although networking behavior is an effective job search method to students, far too little attention has been paid to mechanisms explaining the antecedents and networking behavior. The goal of this study was to demonstrate the effect of the HEXACO personality dimensions on graduated students' job search networking behavior through their network size. A survey of 773 participants was conducted to assess personality traits, network size, and networking behavior. All constructs in the study were measured by 5-point Likert scales. This study employed a structural equation model to examine the proposed conceptual model and the correlations among variables. Results showed that the personality of emotionality negatively influence students' network size, while extraversion and agreeableness are positively associated with the scope of their social network. Second, the findings confirmed that network size is directly related to the level of looking-for job behavior, particularly networking behavior. Finally, our results explored that network size played the mediating effect on how personality traits affect networking behavior. These findings suggest that network size is a dynamic mechanism that helps to understand the correlation between personality traits and job search networking behavior. The theoretical and practical implication of the study, as well as the future research direction were discussed.
\end{abstract}

Keywords: HEXACO Personality Traits, Network Size, Networking Behavior, Job Search, Employment

JEL Classification Code: J60, J62, J64, M12, M54

\section{Introduction}

Over the past decades, much attention has been devoted to the question how personality influence people's career and life quality. Accumulated research evidence suggests that personality is a prominent representation to individuals in terms of work perception, motivation, behavior, job

\footnotetext{
*Acknowledgements:

This research is funded by Vietnam Maritime University.

${ }^{1}$ First Author. Department of Financial Management, Vietnam Maritime University, Haiphong City, Vietnam. Email: mkthanh@vimaru.edu.vn ${ }^{2}$ Corresponding Author. Department of Economics, Vietnam Maritime University, Haiphong City, Vietnam [Postal Address: 484 Lach Tray, Dong Quoc Binh, Le Chan, Hai Phong, Vietnam]

Email: sontungvimaru@gmail.com

${ }^{3}$ Department of Financial Management, Vietnam Maritime University, Haiphong City, Vietnam. Email: pmtrung@vimaru.edu.vn

${ }^{4}$ Department of Economics, Vietnam Maritime University, Haiphong City,

Vietnam. Email: ntthong74@gmail.com

(c) Copyright: The Author(s)

This is an Open Access article distributed under the terms of the Creative Commons Attribution Non-Commercial License (https://creativecommons.org/licenses/by-nc/4.0/) which permits unrestricted non-commercial use, distribution, and reproduction in any medium, provided the unrestricted non-commercial
original work is properly cited.
}

performance and satisfaction, career success, and life quality (Barrick \& Mount, 1991; Fullarton et al., 2013; Hagberg, Hagberg, \& Saveman, 2002; Han, 2020; Huynh et al., 2020; Jalal et al., 2019; Nettle, 2007; Sutin et al., 2009; Wrosch \& Scheier, 2003). Nettle (2007) suggested that personality "what makes you the way you are" - is described as a personal disposition that can predict what they will do. Personality is closely related to employees' work climate perceptions as well as job performance. Fullarton et al. (2013) indicated that employees high in extraversion or agreeableness tend to own high level of work climate perception, which in turn is positively associated with their job performance.

Networking behavior is an informal job search method, but effective and popular (Forret, 2014; Forret \& Dougherty, 2001; Hoye et al., 2009; Lin \& Le, 2019; Wanberg et al., 2000). Forret (2014) reviewed the literature on networking and its relevance for job-search success and confirmed that networking behavior is an effective job search strategy that not only supplies job chances to job seekers, but aslo provides emotional-social supports from friends or acquaintances. Networking behavior is positively proportional to number of job interviews and employment offers, speed of reemployment, person-organization fit, job satisfaction (Forret, 2014). 
Many scholars found evidence of the effect of personality traits on job seekers' the level of networking behavior (Forret \& Dougherty, 2001; Lin \& Le, 2019; Wanberg et al., 2000). For example, Forret and Dougherty (2001) found that extraverted job seekers are inclined to be significantly associated with networking activities such as maintaining social relationships, socializing, while those high in emotionality tend to decrease networking behavior for finding a job (Lin \& Le, 2019). However, the understanding of the mechanism explaining the relationship between personality traits and networking behavior is still lacking.

This study aims to investigate the mediating effect of network size on the relationship between personality traits and graduated students' networking behavior in the job search process. By integrating two theories, individual difference theory and social network theory, this study will demonstrate that personality trait differences can predict variability of network size, which significantly influence job seekers' level of networking behavior.

\section{Review of Literature and Hypothesis}

\subsection{Networking}

Networking behavior is an informal job search method described as contacting family, friends, or acquaintances for asking job information, or employment leads to get a desired job (Wanberg et al., 2000). Previous studies consented that networking method is an effective career management strategy (Forret, 2014; Franzen \& Hangartner, 2006; Hoye et al., 2009; Lin \& Le, 2019; Wanberg et al., 2000). First, social relationships are a valuable resource that can supply job seeker not job information, but also emotional and instrumental supports when facing employment challenges (Brown \& Konrad, 2001; Forret, 2014). Furthermore, a study of Franzen and Hangartner (2006) about using social ties in the job search process revealed that networking behavior is a popular job search strategy in all nations. The research results in 28 countries displayed that the percentage of the job found through social contacts in developed countries such as Japan and the United States is in the middle ( $41 \%$ and $44 \%$, respectively), while this varies significantly in developing nations (e.g. Brazil 67\%, the Philippines 83\%) (Franzen \& Hangartner, 2006). Networking is found to be positively related to short- and long-term job search success consisting of number of job interviews and employment offers (Hoye et al., 2009; Lin \& Le, 2019), job satisfaction and personorganization fit (Hoye et al., 2009; Wanberg et al., 2000).

\subsection{HEXACO Personality Traits and Job Search Networking Behavior}

Based on lexical studies of personality structure in various languages, the personality is best explained by six HEXACO personality traits, consisting of $(\mathrm{H})$ honesty-humility, (E) emotionality, (X) extraversion, (A) agreeableness, (C) conscientiousness, and (O) openness to experience (Ashton et al., 2019), compared to the Big Five model (Costa \& McCrae, 1992). Honesty-humility is defined by honesty, fairness, sincerity, and lack of greed, which is the most difference between the big Five model and the HEXACO model. Three factors of the HEXACO model are closely related to the dimensions of big Five frameworks (extraversion, conscientiousness, and openness to experience). Conversely, agreeableness and emotionality of HEXACO framework overlap significantly with two dimensions of the big Five model (agreeableness and neuroticism). It appears that three factors of the HEXACO (emotionality, extraversion, agreeableness) significantly influence job seekers' networking behavior in looking forjob process.

Lee and Ashton (2004) defined emotionality dimension by fearfulness, anxiety, dependence and sentimentality, which is quite similar with neuroticism trait of Big Five model (presented by anxiety, depression and anger) (Costa \& McCrae, 1992). Prior studies indicated that people in high emotionality appear to lack social skills such as communication, interaction with others due to they are often socially anxious (Selden \& Goodie, 2017; Smółka \& Szulawski, 2011). Furthermore, they who are emotionally unstable tend to rarely initiate to maintain friendship relationships (Selden \& Goodie, 2017). Lin and Le (2019) indicated that emotionality negatively influences job searchers' the level of networking.

The HEXACO extraversion is presented by expressiveness, social boldness, sociability and liveliness (Ashton \& Lee, 2007). Unlike emotionality trait, individuals with high extraversion seem to prefer social engagement and activity, which contribute to developing their social skill (Costa \& McCrae, 1992). Compared to introverted people, those who are extraverted are motivated to find out as well as attend social stimuli (Fishman et al., 2011; $\mathrm{Li}$, et al., 2010). Moreover, they actively find out social interaction and connect with others (Smółka \& Szulawski, 2011). Previous studies demonstrated that individuals high in extraversion are inclined to express the high level of contacting to relationships in their social network (Lin \& Le, 2019; Wanberg et al., 2000).

Agreeableness is described as forgiveness, gentleness, flexibility, and patience (Ashton \& Lee, 2009). Graziano et al. (1996) indicated that individuals with high agreeableness are less likely to perceive conflict in others because they can assuage frustrating situations. In addition, agreeable people have smooth personal interaction, which helps them to build and maintain relationships with others (Ozer \& Benet-Martínez, 2006). Wanberg et al. (2000) suggested that unemployed person with a higher level of agreeableness seems to show a higher level of networking 
intensity than individuals who are in a smaller level of agreeableness. Based on the above logic evidence, we propose that:

H1a: Emotionality will be negatively associated with employment seekers' networking behavior.

H1b: Extraversion will be positively associated with employment seekers' networking behavior.

H1c: Agreeableness will be positively associated with employment seekers' networking behavior.

\subsection{HEXACO Personality Traits and Network Size}

Compared to other personality dimensions, individuals who are high in emotionality, not only have fewer communication skills, but also they frequently have conflicts with others (Demir \& Weitekamp, 2007; Selden \& Goodie, 2017). It appears that they have fewer social relationships or smaller scope of a social network than counterparts who are emotionally stable. There is a growing body of literature that recognises extraversion trait is directly proportional to the scope of social network (Iveniuk, 2018; Molho et al., 2016; Selden \& Goodie, 2017; Wagner et al., 2014). Compared to introverted people, those who are extraverted are motivated to find out as well as attend social stimuli (Fishman et al., 2011; Li, et al., 2010). Moreover, they actively find out social interaction and connect with others (Smółka \& Szulawski, 2011). It is unsurprising to see that they have a larger personal network. Agreeable people have smooth personal interaction, which helps them to build and maintain relationships with others (Ozer \& Benet-Martínez, 2006). Thus, agreeableness positively influence the size as well as the quality of their relationships, especially friendship (Demir \& Weitekamp, 2007). Based on these results, we hypothesize:

H2a: Emotionality will be negatively associated with employment seekers' network size.

$\boldsymbol{H} \mathbf{2 b}$ : Extraversion will be positively associated with employment seekers' network size.

H2c: Agreeableness will be positively associated with employment seekers' network size.

\subsection{Network Size and Networking Behavior}

Although networking behavior benefits to job seekers in many aspects, not all individuals express a high degree of networking behavior. Social network theory suggests that the structure and compositions of the social network are important sources that can predict variability of individuals' social capitals, which contribute in an increase of networking intensity (Adler \& Kwon, 2002). In this study, we will examine job seekers' network size as a key factor that causes differences in terms of networking behavior.

Network size is defined as a number of people that an individual can contact and exchange information in his social network (Seibert et al., 2001). Intuitively, an increase in network size or number of people to consult with leads to an increase in networking intensity, despite an unchanged amount of networking effort. For example, Hoye et al. (2009) found evidence that job seekers' time spent on networking is positively proportional to their network size. Based on the above logic, we propose that job seeker who has a larger network size are inclined to express a higher level of networking behavior than counterparts who own smaller network size.

H3: Employment seekers' network size is positively related to their networking behavior.

\subsection{The Mediating Role of Network Size}

On the basis of the positive effects of network size on networking behavior, and the relationships between personality dimensions of emotionality, extraversion, agreeableness and network size, the study is based on the following hypotheses:

H4a: Social network size mediates the relationship between emotionality and employment seekers' networking behavior.

H4b: Social network size mediates the relationship between extraversion and employment seekers' networking behavior.

H4c: Social network size mediates the relationship between agreeableness and employment seekers'networking behavior.

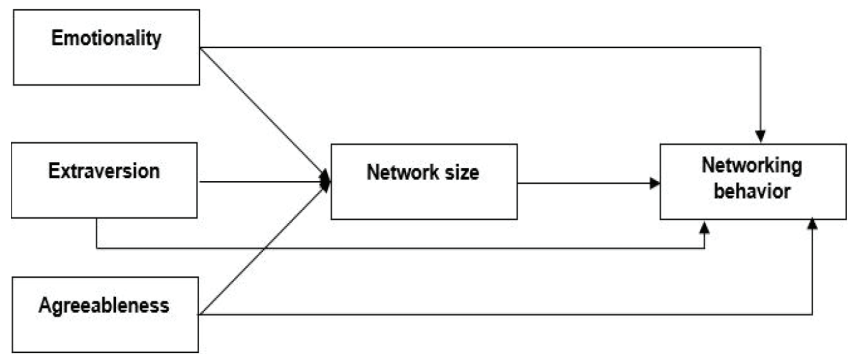

Figure 1: The research framework 


\section{Method}

\subsection{Participants}

Participants were students who graduated three months in different areas, including engineering, accounting, business administration, finance and other areas of study in three universities of Vietnam. We approach student administrators in three universities to get the lists of student email as well as their consent to collect data from their students. We distributed 850 emails that contain the links to the online questionnaires. The surveys were conducted in Vietnamese, which ensures that all participants can understand all questions. We translated the questionnaires into Vietnamese and translated it back in English to approach the accuracy of the translation.

We obtained 773 complete responses, a response rate of $91 \%$. The mean age of participants was 23.22 years (SD $=0.523)$. There was only $3.6 \%$ of married respondents. The percentage of respondents in study areas consisted of $28 \%$ of engineering, $26 \%$ of accounting, $23 \%$ of business administration, $18 \%$ of finance and $5 \%$ of other areas.

\subsection{Measures}

In this study, we measured all items on a 5-point Likert scale ranging from $1=$ strongly disagree to $5=$ strongly agree.

\subsubsection{HEXACO Traits}

Three HEXACO personality dimensions - emotionality, extraversion, and agreeableness - were measured using the 30 items in the short personality inventory built by (Ashton $\&$ Lee, 2009). Each dimension had four facets and was measured by 10 items. An example statement of emotionality is "I worry a lot less than most people do". An example statement of extraversion is as follow "The first thing that I always do in a new place is to make friends". An example statement of agreeableness is "Even when people make a lot of mistakes, I rarely say anything negative". Ashton and Lee (2009) reported the reliability of emotionality, extraversion and agreeableness were $0.78,0.80,0.77$, respectively.

\subsubsection{Network Size}

The scale developed by Hoye et al. (2009) were used to assess network size of job seekers. Following Hoye et al. (2009), we used four items to measure network size $(\alpha=$ 0.88 ). One example statement is "I know a lot of people who might help me find a job".

\subsubsection{Networking Behavior}

Networking behavior for looking for a job $(\alpha=0.93)$ was measured by nine items developed by Wanberg et al. (2000). The example statement are "Contacted people you know to ask for their advice or leads regarding your job search",
"Asked for a referral to someone who might have helpful information or advice about your career or industry".

\subsubsection{Control Variables}

Following previous studies (Lin \& Le, 2019; Thomas et al., 2010; Wanberg et al., 2000), we controlled variables such as gender, age, occupation, strong ties. For example, Wanberg et al. (2000) suggested that the type of occupation affects networking intensity.

\subsection{Analyses}

The data were analyzed with SPSS 22.0 and AMOS 22.0. First, we applied AMOS 22.0 to test the convergent validity and discriminant validity of the latent variables through a series of confirmatory factor analyses (CFAs). Next, we used SPSS 22.0 to test the mean, standard deviations and correlations of all variables. Since this study has multiple independent variables, we used a structural equation modeling approach to test the mediating effect model. To assess the model fit, we applied for the Chi square divided by degrees of freedom $\left(\chi^{2} / \mathrm{df}\right)$, root mean square error of approximation (RMSEA), comparative fit index (CFI), Tucker-Lewis fit index (TLI). Hu and Bentler (1999) suggested a group of criteria of good-of-fit indices as follows: $\chi^{2} / \mathrm{df}$ should be $<3$, a good fit for RMSEA is no $>0.08$, and the cutoff value of CFI and TLI is 0.90 or above.

\section{Results}

\subsection{Scale Validity and Reliability}

We conducted a number of alternative CFAs on the plausible models to test the hypothesized model the most appropriate. Table 2 showed the goodness-of-fit indices of five-factor model and alternative models. The results from Table 2 indicated that the proposed five-factor model had the better indices than all alternative models, $\chi^{2}=857.654$, $\mathrm{df}=562, \chi^{2} / \mathrm{df}=1.526$, RMSEA $=.026$, CFI $=.983$, TLI $=.981$. Thus, the proposed five-factor model was the most appropriate representation of the factor structure of the items.

\subsection{Descriptive Statistics}

Table 1 showed the mean, standard deviation and correlations of all study variables. The results indicated that the personality of emotionality significantly correlated with networking behavior $(r=-.516, p<0.01)$. This means that the higher emotionality was, the less likely graduated students will express networking behavior. Hypothesis la was supported. The significant correlations were also found between extraversion and networking behavior as well as between agreeableness and networking behavior, $(\mathrm{r}=-.434, \mathrm{p}<0.01)$ and $(\mathrm{r}=-.279, \mathrm{p}<$ 0.01 ), respectively. This means that the higher extraversion and agreeableness personalities were, the more likely students will have networking behavior. Hypothesis $1 \mathrm{~b}, 1 \mathrm{c}$ were supported. 
Khac Thanh MAI, Son-Tung LE, Manh-Trung PHUNG, Thi Thuy Hong NGUYEN /

Journal of Asian Finance, Economics and Business Vol 7 No 12 (2020) 545-553

Table 1: Descriptive statistics and inter-correlations among variables

\begin{tabular}{|l|c|c|c|c|c|c|c|c|}
\hline Variables & Mean & SD/ $\boldsymbol{\alpha}$ & AVE/C. $\boldsymbol{R}$ & $\mathbf{1}$ & $\mathbf{2}$ & $\mathbf{3}$ & $\mathbf{4}$ & $\mathbf{5}$ \\
\hline 1. Emotionality & 3.27 & $0.64 / 0.89$ & $0.51 / 0.89$ & 1 & & & & \\
\hline 2. Extraversion & 3.85 & $0.55 / 0.91$ & $0.52 / 0.91$ & -.016 & 1 & & & \\
\hline 3. Agreeableness & 3.96 & $0.54 / 0.90$ & $0.54 / 0.90$ & $-.134^{* *}$ & $.170^{* *}$ & 1 & & \\
\hline 4. Network size & 3.34 & $0.59 / 0.88$ & $0.57 / 0.89$ & $-.191^{* *}$ & $.212^{* *}$ & $.226^{* *}$ & 1 & \\
\hline 5. Networking behavior & 3.98 & $0.52 / 0.93$ & $0.65 / 0.93$ & $-.516^{* *}$ & $.434^{* *}$ & $.279^{* *}$ & $.407^{* *}$ & 1 \\
\hline
\end{tabular}

$N=773$. Note. ${ }^{*} p<.01 . S D=$ Standard Deviation, $\alpha=$ Cronbach's Alpha, AVE = Average Variance Extracted, C.R = Composite Reliability

Table 2: Confirmatory factor analysis (CFA) of discrimination validity

\begin{tabular}{|l|l|c|c|c|c|c|c|c|}
\hline Models & \multicolumn{1}{|c|}{ Factors } & \multicolumn{1}{|c|}{$\mathbf{X}^{2}$} & df & $\mathbf{X}^{2} / \mathrm{df}$ & RMSEA & $\Delta \mathbf{X}^{2}$ & CFI & TLI \\
\hline Model 1 & $\begin{array}{l}\text { 5 factors: EM, EX, AG, } \\
\text { NS, NB }\end{array}$ & 857.654 & 562 & 1.526 & .026 & - & .983 & .981 \\
\hline Model 2 & $\begin{array}{l}\text { 4 factors: EM + EX, AG, } \\
\text { NS, NB }\end{array}$ & 3168.341 & 566 & 5.598 & .077 & 2310.687 & .854 & .758 \\
\hline Model 3 & $\begin{array}{l}\text { 3 factors: EM + EX+ } \\
\text { AG, NS, NB }\end{array}$ & 5334.803 & 569 & 9.376 & .104 & 2166.462 & .732 & .653 \\
\hline Model 4 & $\begin{array}{l}\text { 2 factors: EM + EX+AG } \\
+ \text { NS, NB }\end{array}$ & 6724.143 & 571 & 11.776 & .118 & 1389.340 & .654 & .601 \\
\hline Model 5 & $\begin{array}{l}\text { 1 factors: EM + EX + AG } \\
+ \text { NS + NB }\end{array}$ & 7622.366 & 572 & 13.326 & .126 & 898.223 & .603 & .563 \\
\hline
\end{tabular}

Note: $N=773$. EM: Emotionality; EX: Extraversion; AG: Agreeableness, NS: Network size; NB: Networking behavior. $\Delta \mathrm{X} 2$ tests are between the five-factor model and each alternative model.

+ represents factors merge into one factor.

The results indicated that network size had the significant correlation with networking behavior $(\mathrm{r}=.407, \mathrm{p}<0.01)$, which refers that the more students have the scope of the social network, the more likely they will express networking behavior. Hypothesis 3 was confirmed.

Table 1 exhibited that emotionality $(\mathrm{r}=-.191, \mathrm{p}<0.01)$, extraversion $(\mathrm{r}=.212, \mathrm{p}<0.01)$ and agreeableness $(\mathrm{r}=.226$, $\mathrm{p}<0.01)$ were correlated with network size. This means that the fewer job seekers were in emotionality, and the more job seekers were in extraversion and agreeableness, the larger their network was. Thus, hypothesis $2 \mathrm{a}, 2 \mathrm{~b}$, and $2 \mathrm{c}$ were supported.

\subsection{Testing the Mediating Effect}

The path analysis of Structural Equation Model (SEM) was used to test the correlation between the HEXACO personality dimensions and job search networking behavior through network size. The model fits the data well: $\chi^{2}=$ $857.654, \mathrm{df}=562, \chi^{2} / \mathrm{df}=1.526, \mathrm{RMSEA}=.026, \mathrm{CFI}=.983$,
$\mathrm{TLI}=.981, \mathrm{GFI}=.942, \mathrm{AGFI}=.932$, which were all $>.900$. This means that the goodness-of-fit indices of the theoretical model were desirable (Hu \& Bentler, 1999) (see Figure 2).

Table 3 displayed that the total, direct and indirect effects of three dimensions of the HEXACO personality on networking behavior through network size. The results indicated that extraversion had the greatest direct effect on networking behavior $(\mathrm{r}=.331, \mathrm{p}<0.001)$, followed by emotionality $(\mathrm{r}=-.303, \mathrm{p}<0.001)$, while agreeableness had the smallest effect $(r=.094, p<0.01)$ (Table 3). Besides, all three personality dimensions of emotionality, extraversion, agreeableness had the indirect effects on networking behavior through network size $(\mathrm{r}=-.025, \mathrm{p}<0.001)$, ( $\mathrm{r}$ $=.033, \mathrm{p}<0.001),(\mathrm{r}=.032, \mathrm{p}<0.01)$, respectively. In general, network size partially mediates three HEXACO personalities on networking. That is, individuals who are low in emotionality or high in extraversion and agreeableness are inclined to own the larger size of the social network, which in turn positively influence the level of networking behavior for finding employment. 
Table 3: Total effect, direct effect and indirect effect.

\begin{tabular}{|l|c|c|c|}
\hline & \multicolumn{3}{|c|}{$95 \%$ BCa (5.000 bootstraps) } \\
\hline & $\begin{array}{c}\text { Total } \\
\text { effect }\end{array}$ & $\begin{array}{c}\text { Direct } \\
\text { effect }\end{array}$ & $\begin{array}{c}\text { Indirect } \\
\text { effect by } \\
\text { network } \\
\text { size }\end{array}$ \\
\hline $\begin{array}{l}\text { Emotionality - } \\
\text { networking behavior }\end{array}$ & $-.328^{* * *}$ & $-.303^{* * *}$ & $-.025^{* * *}$ \\
\hline $\begin{array}{l}\text { Extraversion - } \\
\text { networking behavior }\end{array}$ & $.364^{* * *}$ & $.331^{* * *}$ & $.033^{* * *}$ \\
\hline $\begin{array}{l}\text { Agreeableness - } \\
\text { networking behavior }\end{array}$ & $.126^{* * *}$ & $.094^{* *}$ & $.032^{* *}$ \\
\hline
\end{tabular}

${ }^{* *} p<.01,{ }^{* * *} p<.001$.

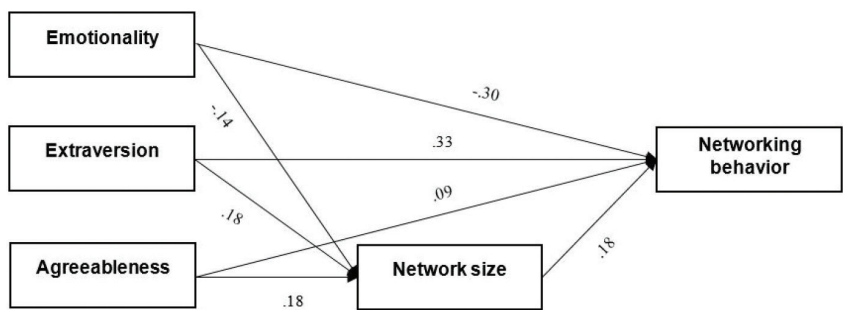

Figure 2: The standardized path coefficient of the hypothesized model

\section{Discussion}

This research aims to explore the effect of HEXACO personality dimensions on graduated students' networking behavior through their network size in the finding-job process. The study test four hypotheses: (1) three HEXACO personality traits would be associated with job search networking behavior, (2) three HEXACO personality traits would be associated with network size, (3) network size would be associated with job search networking behavior, and (4) network size would mediate the relationship between the dimensions of HEXACO personality and networking behavior. All hypotheses were supported.

Based on the social network theory, social relationships not only can supply much job opportunities, but help job seekers in terms of emotional and instrumental support (Forret, 2014). It seems that individuals who own the larger size of the social network will have more advantage in finding employment through asking friends, relatives or acquaintances. Correlational results showed that network size was positively related to the level of networking behavior, which was consistent with previous studies (Hoye et al., 2009; Lin \& Le, 2019). As to the relationship between the HEXACO personality and networking behavior for finding employment, emotionality was significantly negatively related to networking behavior, while extraversion and agreeableness were significantly positively related to networking. Compared to agreeableness personality, extraversion was closer to networking behavior. These results were similar to previous research (Lin \& Le, 2019). Besides, the individual difference theory explained that personal difference may make dissimilar social behavior, attitudes, and interaction among individuals (Lin \& Le, 2019; Wanberg et al., 2000). Our findings also suggested that three personality dimension of emotionality, extraversion, and agreeableness can significantly influence students' network size. Unlike emotionality that negatively influences network size, extraversion and agreeableness were positive antecedents in predicting students' network size. As high order traits, each scale of the HEXACO personality has four separate secondary structures. Such as emotionality includes fearfulness, anxiety, dependence, sentimentality; extraversion includes social self-esteem, social boldness, sociability, liveliness; agreeableness includes forgiveness, gentleness, flexibility, patience. From the secondary structure of the high-order structure of the HEXACO personality, it appears that extraversion was more appropriate to network intensity and development than agreeableness. And, fearfulness and anxiety (lower-order of emotionality) were likely to have a negative effect on the social relationship and interaction behavior. Therefore, in future research, the relationship between the secondary structure of HEXACO personality and network size as well as networking behavior should be explored.

The most important finding of this research is that network size acted as a mediator of the relationship between HEXACO personality dimensions (emotionality, extraversion, and agreeableness) and networking behavior for finding jobs. This study supports the individual difference theory and provides a new perspective for explaining the mechanism how the personality traits affect the level of networking behavior in graduated students' the employment process. Our results demonstrated that high emotional job seekers are inclined to lack social interaction skills and passively maintain relationships, which is related to a small size of the network. While individuals who high in extraversion or agreeableness tend to own the large network size. Network size in turn is positively related to the level of netwoking behavior. Based on the results mentioned above, we can draw the conclusion that network size play the mediating effect on the relationship between emotionality, extraversion, and agreeableness and job search networking behavior.

Several limitations of this study should be noted. First, this study uses cross-sectional research to explore the effect of three personality dimensions on networking behavior through network size, which may not be able to find the causal relationship between variables. In future research, scholars should use longitudinal research to further explore. 
Second, this research appears to be limited by factors such as working years, economic conditions, tie strength or education. For example, Lin and Le (2019) confirmed that people would help their family or close friends (strong ties) than acquaintances (weak ties), which also predict variability of job seekers' networking behavior. Further research can explore the effect of these factors on network size as well as networking behavior of job seekers in the job search process. Thirdly, this study failed to examine the role of networking behavior on employment outcomes such as number of employment offers, person-job fit, employment satisfaction. Therefore, researchers should explore the relationship between personality traits and networking behavior as well as further variables (number of job interviews, number of employment offers, employment satisfaction) in the future.

Despite these above limitations, our study is the first to investigate the mediating effect of network size on the relationship between HEXACO personality traits and students' networking behavior. The study provides important understandings about the links between HEXACO traits, network size, and networking behavior in the employment process. The social network theory suggests that social relationships are considered as social capital that can bring benefit in term of information, support, and other resources (Granovetter, 1973; Hoye et al., 2009; Lin \& Le, 2019; Wanberg et al., 2000). This study demonstrated that network size directly influences students' level of networking behavior, which in turn is positively related to number of job interviews and job offers, insurance benefit (Hoye, et al., 2009; Wanberg et al., 2000). Besides, the study found the relationship between three personality traits and network size. While emotionality is negatively related to network size, extraversion and agreeableness play the role in increasing individuals' the scope of the social network. This could have implications for educators and career counsellors. Beyond students' competencies like knowledge, skills, abilites (Trisnaningsih et al.2020), educators should find training interventions to their personality traits for increasing the success level of looking for a job; for example, controlling emotionality or encouraging extraversion and agreeableness.

\section{References}

Adler, P. S., \& Kwon, S. W. (2002). Social capital: Prospects for a new concept. Academy of Management Review, 27, 17-40. doi:10.5465/amr.2002.5922314

Ashton, M. C., \& Lee, K. (2007). Empirical, theoretical, and practical advantages of the HEXACO model of personality structure. Personality and Social Psychology Review, 11, 150166. doi:10.1177/1088868306294907

Ashton, M. C., \& Lee, K. (2009). The HEXACO-60: A short measure of the major dimensions of personality. Journal of Personality Assessment, 91(4), 340-345. doi:10.1080/00223890902935878
Ashton, M. C., Lee, K., \& Visser, B. A. (2019). Where's the H? Relations between BFI-2 and HEXACO-60 scales. Personality and Individual Differences, 137, 71-75. doi:10.1016/j. paid.2018.08.013

Ashton, M. C., Lee, K., Perugini, M., Szarota, P., Vries, R. E., Blas, D. L., . . . Raad, B. D. (2004). A six-factor structure of personality-descriptive adjectives: solutions from psycholexical studies in seven languages. Journal of Personality and Social Psychology, 86(2), 356-366. doi:10.1037/0022-3514.86.2.356

Barrick, M. R., \& Mount, M. K. (1991). The big five personality dimensions and job performance: A meta-analysis. Personnel Psychology, 44(1), 1-26. doi:10.1111/j.1744-6570.1991. tb00688.x

Breevaart, K., \& De Vries, R. E. (2019). Followers' HEXACO personality traits and preference for charismatic, relationshiporiented, and task-oriented leadership. Journal of Business and Psychology. doi:10.1007/s10869-019-09671-6

Brown, D. W., \& Konrad, A. M. (2001). Granovetter was right: The importance of weak ties to a contemporary job search. Group \& Organization Management, 26, 434-462. doi:10.1177/1059601101264003

Cannata, M. (2011). The Role of Social Networks in the Teacher Job Search Process. The Elementary School Journal, 111(3), 477-500. doi:10.1086/657656

Conger, J. A. (1999). Charismatic and transformational leadership in organizations: An insider's perspective on these developing streams of research. The Leadership Quarterly, 10(2), 145-179. doi:10.1016/S1048-9843(99)00012-0

Costa, P. T., \& McCrae, R. R. (1992). Normal personality assessment in clinical practice: The NEO Personality Inventory. Psychological Assessment, 4(1), 5-13. doi:10.1037/10403590.4.1.5

De Vries, R. E. (2008). What are we measuring? Convergence of leadership with interpersonal and non-interpersonal personality. Leadership, 4(4), 403-417. doi:10.1177/1742715008095188

Demir, M., \& Weitekamp, L. A. (2007). I am so happy cause today I found my friend: Friendship and personality as predictors of happiness. Journal of Happiness Studies, 8(2), 181-211. doi:10.1007/s10902-006-9012-7

Fishman, I., Ng, R., \& Bellugi, U. (2011). Do extraverts process social stimuli differently from introverts? Cognitive neuroscience, 2(2), 67-73. doi:10.1080/17588928.2010.5274 34

Forret, M. L. (2014). Networking as a job-search behavior and career management strategy. In U.-C. Klehe, \& E. Van Hooft, The Oxford Handbook of Job Loss and Job Search (pp. 275-291). Oxford University Press. doi:10.1093/ oxfordhb/9780199764921.013.022

Forret, M. L., \& Dougherty, T. W. (2001). Correlates of networking behavior for managerial and professional employees. Group \& Organization Management, 26, 283-311. doi:10.1177/1059601101263004 
Franzen, A., \& Hangartner, D. (2006). Social networks and labour market outcomes: The non-monetary benefits of social capital. European Sociological Review, 22(4), 353-368. doi:10.1093/ esr/jcl001

Fullarton, C., Fuller-Tyszkiewicz, M., \& Treuer, K. V. (2013). The mediating role of work climate perceptions in the relationship between personality and performance. 23(4), 525-536. doi:10.1 080/1359432X.2013.764601

Granovetter, M. S. (1973). The strength of weak ties. American Journal of Sociology, 78, 1360-1380.

Graziano, W. G., Jensen-Campbell, L. A., \& Hair, E. C. (1996). Perceiving interpersonal conflict and reacting to it: the case for agreeableness. Journal of Personality and Social Psychology, 70(4), 820-835. doi:10.1037//0022-3514.70.4.820

Hagberg, M., Hagberg, B., \& Saveman, B.-I. (2002). The significance of personality factors for various dimensions of life quality among older people. Aging and Mental Health, 6(2), 178-185. doi:10.1080/13607860220126754

Han, H. J. (2020). The effects of personality traits on subjective well-being and behavioral intention associated with serious leisure experiences. Journal of Asian Finance, Economics and Business, 7(5), 167-176. doi:10.13106/jafeb.2020.vol7.no5.167

Hoye, G. V., Hooft, E. V., \& Lievens, F. (2009). Networking as a job search behaviour: A social network perspective. Journal of Occupational and Organizational Psychology, 82, 661-682. doi:10.1348/096317908X360675

Hu, L., \& Bentler, P. M. (1999). Cutoff criteria for fit indexes in covariance structure analysis: Conventional criteria versus new alternatives. Structural Equation Modeling, 6(1), 1-55. doi:10.1080/10705519909540118

Huynh, T. L., Nguyen, H. M., \& Kieu, T. T. (2020). The impact of salesperson's personality to job performance in machinery industry in Viet Nam. Journal of Asian Finance, Economics and Business, 7(10), 377-389. doi:10.13106/jafeb.2020.vol7. no10.377

Iveniuk, J. (2018). Social networks, role-relationships, and personality in older adulthood. The Journals of Gerontology: Series B, 74(5), 815-826. doi:10.1093/geronb/gbx120

Jalal, R. N.-U.-D., Zeb, N., \& Fayyaz, U.-E.-R. (2019). The Effect of Personality traits on employee job satisfaction with moderating role of islamic work ethics. Journal of Asian Finance, Economics and Business, 6(2), 161-171. doi:10.13106/ jafeb.2019.vol6.no2.161

Kramer, A., Bhave, D. P., \& Johnson, T. D. (2014). Personality and group performance: The importance of personality composition and work tasks. Personality and Individual Differences, 58, 132-137. doi:10.1016/j.paid.2013.10.019

Lee, K., \& Ashton, M. C. (2004). Psychometric properties of the HEXACO personality inventory. 39(2), 329-358. doi:10.1207/ s15327906mbr3902_8

Li, J., Tian, M., Fang, H., Xu, M., Li, H., \& Liu, J. (2010). Extraversion predicts individual differences in face recognition.
Communicative \& Integrative Biology, 3(4), 295-298. doi:10.4161/cib.3.4.12093

Lin, S.-P., \& Le, S.-T. (2019). Predictors and outcomes of Vietnamese university graduates'networking behavior as job seekers. Social behavior and Personality, 47(10), 1-11. doi:10.2224/sbp.8379

Marin, A. (2012). Don't mention it: Why people don't share job information, when they do, and why it matters. Social Networks, 34(2), 181-192. doi:10.1016/j.socnet.2011.11.002

Molho, C., Roberts, S. G., de Vries, R. E., \& Pollet, T. V. (2016). The six dimensions of personality (HEXACO) and their associations with network layer size and emotional closeness to network members. Personality and Individual Differences, 99, 144-148. doi:10.1016/j.paid.2016.04.096

Nettle, D. (2007). Personality: What makes you the way you are. Oxford: Oxford University Press.

O'Connor, L. T. (2013). Ask and you shall receive: Social network contacts' provision of help during the job search. Social Networks, 35(4), 593-603. doi:10.1016/j. socnet.2013.07.005

Ozer, D. J., \& Benet-Martínez, V. (2006). Personality and the prediction of consequential outcomes. Annual Review of Psychology, 57, 401-421. doi:10.1146/annurev. psych.57.102904.190127

Seibert, S. E., Kraimer, M. L., \& Liden, R. C. (2001). A social capital theory of career success. Academy of Management Journal, 44, 219-237. doi:10.5465/3069452

Selden, M., \& Goodie, A. S. (2017). Review of the effects of Five Factor Model personality traits on network structures and perceptions of structure. Social Networks, 52, 81-99. doi:10.1016/j.socnet.2017.05.007

Smółka, P., \& Szulawski, M. (2011). Personality traits and motivational traits as predictors of social competence: Implication for occupational selection process. Edukacja Ekonomistów I Menedżerów, 22(4), 111-126. doi:10.5604/01.3001.0009.5542

Sutin, A. R., Costa, P., Miech, R., \& Eaton, W. W. (2009). Personality and career success: Concurrent and longitudinal relations. European Journal of Personality, 23(2), 71-84. doi:10.1002/per.704

Thomas, J. P., Whitman, D. S., \& Viswesvaran, C. (2010). Employee proactivity in organizations: A comparative meta-analysis of emergent proactive constructs. Journal of Occupational and Organizational Psychology, 83(2), 275-300. doi:10.1348/096317910X502359

Totterdell, P., Holman, D., \& Hukin, A. (2008). Social networkers: Measuring and examining individual differences in propensity to connect with others. Social Networks, 30(4), 283-296. doi:10.1016/j.socnet.2008.04.003

Trisnaningsih, S., Sutrisno, S., Permatasari, Y., Hendrak, F. H., \& Sulistyowati, E. (2020). Contingency model to increase the uptake of higher education graduates in the job market. Journal 
of Asian Finance, Economics and Business, 7(4), 197-203. doi:10.13106/jafeb.2020.vol7.no4.197

Wagner, J., Lüdtke, O., Roberts, B. W., \& Trautwein, U. (2014). Who belongs to me? social relationship and personality characteristics in the transition to young adulthood. European Journal of Personality, 28(6), 586-603. doi:10.1002/per.1974

Wanberg, C. R., Kanfer, R., \& Banas, J. T. (2000). Predictors and outcomes of networking intensity among unemployed job seekers. Journal of Applied Psychology, 85, 491-503. doi:10.1037/0021-9010.85.4.491
Wright, K. B., \& Miller, C. (2010). A measure of weak-tie/strongtie support network preference. Communication Monographs, 77(4), 500-517. doi:10.1080/03637751.2010.502538

Wrosch, C., \& Scheier, M. F. (2003). Personality and quality of life: The importance of optimism and goal adjustment. Quality of Life Research, 12, 59-72. doi:10.1023/A:1023529606137

Zhu, X., Woo, S. E., Porter, C. M., \& Brzezinski, M. (2013). Pathways to happiness: From personality to social networks and perceived support. Social Networks, 35(3), 382-393. doi: 10.1016/j.socnet.2013.04.005 